\title{
Comparative study of antimicrobial prescribing pattern between Nepal and Pakistan
}

Muhammad Umer Nadeem ${ }^{1}$, Ram Bahadur Dhami ${ }^{1}$, Krishna Prasad Dahal ${ }^{1}$, Devi Ram Pokharel ${ }^{1}$, Anil Kumar Singh ${ }^{1}$, Imdad Hushain Khan ${ }^{1}$, Nibandha Prasad Chaulagai ${ }^{1}$, Bimal Gharti Magar ${ }^{1}$, Balika Acharya', Inaam Ur Rehman', Zikria Saleem ${ }^{1,2,3}$

\section{Abstract}

Objective: The purpose of this cross-sectional study conducted in different private and public sector hospitals of the major cities of Nepal and Pakistan was to compare and evaluate the antibiotic prescribing patterns.

Methods: The data was collected based on prescriptions received from different hospitals of Lahore, Pakistan and Kathmandu, Nepal without much interaction with the patients.

Results: Out of a total of 272 patients, 111 (40.8\%) patients from Nepal and 161 (59.19\%) patients from Pakistan were prescribed with 447 antibiotics. In both countries, out of total antibiotics prescribed, $42.30 \%$ were $3^{\text {rd }}$ generation cephalosporins. Also, in Pakistan and Nepal, out of all the indications, $49.2 \%$ of the antibiotics were given as medical prophylaxis.

Conclusion: In Pakistan, the antimicrobial prescription rate is comparatively $7.2 \%$ higher than Nepal, and in both countries, there is a need of proper implementation of antibiotic prescribing guidelines for the prescription and the administration of antibiotics as medical prophylaxis.
1 University College of Pharmacy, University of the Punjab, Pakistan.

2 School of Pharmaceutical Sciences, Universiti Sains Malaysia, Malaysia.

3 Department of Pharmacy, University of the Lahore, Pakistan.

Contact information:

\section{DR. Zikria Saleem.}

Address: Department of Pharmacy, University of the Lahore, Pakistan. Tel: $+92322-9801981$.

Fax: +92-42-99211624.

巨x xikria@gmail.com 


\section{Introduction}

Introduction of antibiotics in modern medicine is regarded as the 'wonder'. Various infectious diseases such as syphilis, gonorrhea, leprosy, tuberculosis, etc. used to be epidemic and killed millions of people worldwide and the powerful impact of these antibiotics sparked a revolution in the discovery of new drugs [1]. Besides the use of antibiotics these days, antimicrobial resistance is the main drawback, and this is regarded as the alarming problem currently, which is to be addressed properly. Flawed assumptions, faulty practices, antibiotic consumptions, and somehow contribution of self-medication made inevitable increment of drug resistance much sooner, rather than later. Irrational and inappropriate use of antimicrobials is by far the biggest driver of drug resistance. This includes overuse, underuse and misuse of antibiotics [1]. The key strategy to control antibacterial resistance is the appropriate use of the antibiotics and identification of major problems in antibiotics prescription especially in primary health care facilities where most patients receive medical care [2].

The cross country variations study in Europe and Canada shows that the socioeconomic factors mostly affect antibiotics prescription and its use across countries [3, 4]. It is also noted that environmental factors also have a role to play in the way how medicines/antibiotics are used in the population [5]. The rapid environmental change and weather-related change due to its geographical location are associated with a change in bacterial strains resulting in bacterial resistance towards antibiotics [6].

Many Low and Middle-Income Countries (LMICs) have questionable access to essential medicines. The data from LMICs is often weak, fragmented, and requires collation [7]. In a developing country such as Nepal and Pakistan, where there is excessive use of antibiotics, there is an increased risk of antibiotic resistance to the microbes causing va- rious community and hospital-acquired infection. The high prevalence of antimicrobial resistance was observed against certain common bacterial clinical isolates (Staphylococcus aureus, E. coli) for the commonly used antibiotics like amoxicillin, cotrimoxazole, fluoroquinolones and third-generation cephalosporins in Nepal and Pakistan [8, 9]. There must be proper follow of standard guidelines, and the prescriber should have proper knowledge of the biology of microbes. Besides, consumers should be properly educated about the regimen of antibiotics and self-consuming of the antibiotics should be discouraged and prevented.

The main purpose of our study is to compare the antibiotic prescription pattern in developing countries of Pakistan and Nepal, analyze the variation in prescription.

\section{Methods}

\section{Study Centre}

This cross-sectional study was conducted in different private and public sector hospitals of major cities of Nepal and Pakistan which include Lahore and Kathmandu.

\section{Approval}

For the smooth and efficient study of the infection of various diseased conditions in those hospitals, we took the formal approval letter from the Punjab university college of pharmacy and were sent to the respective hospital and we started a collection of the prescription. Those hospitals comprise of 25 beds to 225 beds. For the collection of prescription from the respective hospital, we went to that hospital and showed the letter of approval to the head of the pharmacy of those hospitals, and after taking the permission, we observe the prescription and then the findings were filled in the proforma. 


\section{Study duration}

The data was collected from both countries simultaneously during the duration $1^{\text {st }}$ November 2017 to $31^{\text {st }}$ January 2018.

\section{Study population}

We observed the prescription of all the hospitalized patient in the surgical ward, post-operation ward, intensive care unit, general ward, angiography ward in Pakistan and as well as the emergency ward \& outpatient of that hospital in Nepal.

We filled the table by evaluating the prescription of individual patients those who were prescribed antimicrobials agents which were registered in the record of that respective hospitals. These evaluations were performed during 12 weeks between November 2017 to January 2018, in Pakistan during November and December 2017 of the different ward of hospitals mentioned above. Similarly, from Nepal, we allocate the different health care personnel of different hospital to send the picture of the prescription of their hospitals, and the required data were observed and collected.

The following patient's information was recorded: sex, surgical procedure, ward name, hospital admission date, length of hospital stay, catheterization procedure (Urinary, peripheral, central, other, none) and intubation (ETI, NGT, others specify none), patient factor (immunosuppressant, neutropenia, HIV), culture order/report (no, yes/specify time) if yes than culture sample type and causative agent was specified in case of ward patients and patients with current antimicrobial therapy including antibiotics, antifungal, antiviral, anticancer, antiprotozoal. We recorded the main diagnosis, name of the antimicrobial prescribed (dose, duration, route of administration, the reason behind prescribing) and its indications either according to the guidelines or not and the categorization of antimicrobial agent used according to WHO. We also record whether the drug was used for the prophylaxis (medical/surgical) or infection (hospital-acquired/community-acquired) purpose. The prescription was determined whether the treatment is empirical (when the causative agent is unknown) or targeted (in case of known bacterial infection). Furthermore, all prescription was checked whether the treatment is a targeted basis or empirical basis.

\section{Results}

A total of two hundred and seventy-two (272) ambulatory and admitted patients prescription were included in this study from the various government and private hospitals of Nepal and Pakistan, out of which one hundred and eleven (111) were from Nepal and one hundred and sixty-one (161) from Pakistan who has prescribed four hundred and forty-seven (447) antimicrobial agents. Out of 272 patients, one hundred and twenty (120) [41 from Nepal and 79 from Pakistan], female patients were prescribed (43.1\%) (197) of total antimicrobial agent's [33.6\% from Nepal and 50.6\% from pakistan], while two hundred and fifty (250) $(54.7 \%)$ of total antimicrobial agents were prescribed for (152) one hundred and fifty-two male patients [70 from Nepal and 82 from Pakistan] as shown in Figure 1.

Figure 1: Total antimicrobial agent prescribed to male and female patients.

Gender Wise Antibiotic Use

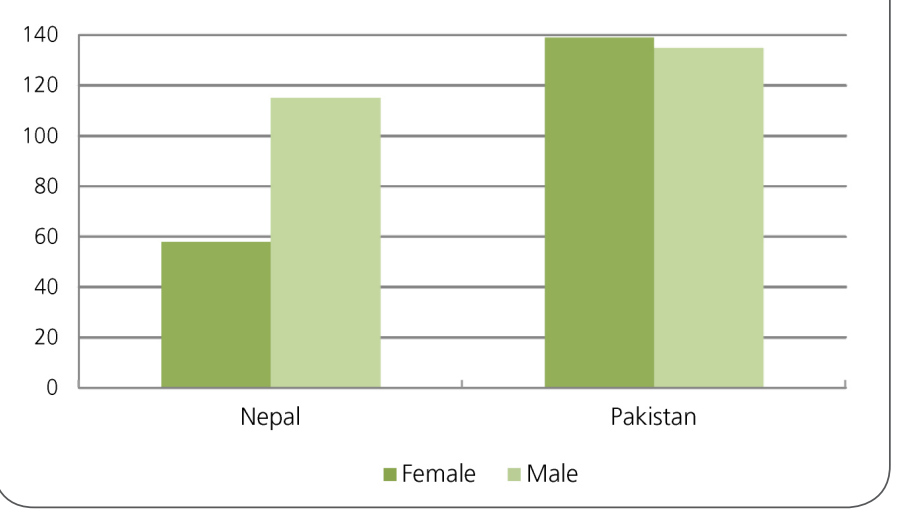


This study illustrates us that out of the total antimicrobial agent prescribed contains; $42.30 \% 3^{\text {rd }}$ generation cephalosporin (198/447), (69/173 in Nepal and 129/274 in Pakistan), 16.11\% penicillins (72/447) [31/173 in Nepal and 41/274 in Pakistan), $11.63 \%$ antiprotozoal (52/447) (16/173 in Nepal and 36/274 in Pakistan), $7.83 \%$ quinolones (35/447) [11/173 in Nepal and 24/274 in Pakistan], 4.92\% macrolides (22/447) [15/173 in Nepal and 7/274 in Pakistan], 4.70\% aminoglycosides (21/447) [9/173 in Nepal and 12/274 in Pakistan], 2.24\% carbapenem (10/447) [1/173 in Nepal and 9/274 in Pakis$\tan ], 1.79 \% 2^{\text {nd }}$ generation cephalosporins (8/447) [3/173 in Nepal and 5/274 in Pakistan], 1.34\% tetracycline (6/447) [5/173 in Nepal and 1/274 in Pakistan], 1.12\% anti-tubercular drug (5/447) [4/173 in Nepal and1/274 in Pakistan], 0.89\% antifungal, antihelmenthics and vancomycin (4/447) [4/173 antihelmenthics and 3/173 antifungal in Nepal and $1 / 274$ antihelmenthics and 4/274 vancomycin in Pakistan respectively) and $0.45 \%$ of $4^{\text {th }}$ generation cephalosporins,sulfonamides and linezolide (2/447) $\left[1 / 173\right.$ and $1 / 2744^{\text {th }}$ generation cephalosporins and sulfonamides in both countries and 2/274 linezolides in Pakistan only] were prescribed for 272 patients in both nations for treating antimicrobial infections as shown in Table 1.

The indications in which antimicrobials were prescribed were mainly in medical prophylaxis $49.2 \%$ (220/447) [60.1\% (104/173) in Nepal and 42.3\% $(116 / 274)$ in Pakistan] followed by surigcal prophylaxis 20.6\% (92/447) [1.2\% (2/173) in Nepal and $32.8 \%(90 / 274)$ in Pakistan] and respiratory tract infections 13.4\% (60/447) [19.7\% (34/73) in Nepal and $9.5 \%(26 / 274)$ in Pakistan] as shown in Table 2. Table 3 illustrates that the among the 3rd generation cephalosporins, ceftriaxone was the mostly used antibiotic 30.6\% (140/447) [22.5\% (39/173) in Nepal and 36.9\% (101/274) in Pakistan] followed by metronidazole 11.4\% (52/447) [9.2\% (16/173) in Nepal and 13.1\% (36/274) in Pakistan] and, amoxicillin and clavulanic acid 7.7\% (35/447) [6.9\% (12/1733) in Nepal and 8.4\% (23/274) in Pakistan]. Table 4
Table 1. Antimicrobial agents prescribed.

\begin{tabular}{|l|c|c|c|c|c|c|}
\hline \multirow{2}{*}{ Antibiotics } & \multicolumn{2}{|c|}{ Nepal } & \multicolumn{3}{|c|}{ Pakistan } & \multicolumn{2}{c|}{ Total } \\
\hline & $\mathbf{n}$ & $\%$ & $\mathbf{n}$ & $\%$ & $\mathbf{n}$ & $\%$ \\
\hline Penicillin & 31 & 17.9 & 41 & 14.9 & 72 & 16.11 \\
\hline Carbapenem & 1 & 0.5 & 9 & 3.2 & 10 & 2.24 \\
\hline $\begin{array}{l}\text { Macrolides } \\
\text { 2nd Generation }\end{array}$ & 15 & 8.6 & 7 & 2.5 & 22 & 4.97 \\
\hline Cephalosporins & 3 & 1.7 & 5 & 1.8 & 8 & 1.79 \\
\hline $\begin{array}{l}\text { 3d Generation } \\
\text { Cephalosporins }\end{array}$ & 69 & 39.8 & 129 & 47 & 198 & 44.30 \\
\hline $\begin{array}{l}\text { 4h Generation } \\
\text { Cephalosporins }\end{array}$ & 1 & 0.5 & 1 & 0.36 & 2 & 0.45 \\
\hline Quinolones & 11 & 6.3 & 24 & 8.75 & 35 & 7.83 \\
\hline Sulfonamides & 1 & 0.5 & 1 & 0.36 & 2 & 0.45 \\
\hline Aminoglycosides & 9 & 5.2 & 12 & 4.3 & 21 & 4.70 \\
\hline Anti. TB & 4 & 2.3 & 1 & 0.36 & 5 & 1.12 \\
\hline Tetracycline & 5 & 2.8 & 1 & 0.36 & 6 & 1.34 \\
\hline Antifungal & 3 & 1.7 & 1 & 0.36 & 4 & 0.89 \\
\hline Anthelminthic & 4 & 2.3 & 0 & 0 & 4 & 0.89 \\
\hline Antiprotozoal & 16 & 9.2 & 36 & 13.1 & 52 & 11.63 \\
\hline Linezolid & 0 & 0 & 2 & 0.7 & 2 & 0.45 \\
\hline Vancomycin & 0 & 0 & 4 & 1.45 & 4 & 0.89 \\
\hline Total & 173 & 100 & 274 & 100 & 447 & 100 \\
\hline
\end{tabular}

Table 2. Indications of antimicrobial agents prescribed.

\begin{tabular}{|l|c|c|c|c|c|c|}
\hline \multirow{2}{*}{ Indication } & \multicolumn{2}{|c|}{ Nepal } & \multicolumn{3}{c|}{ Pakistan } & \multicolumn{2}{c|}{ Total } \\
\cline { 2 - 8 } & $\mathbf{n}$ & $\%$ & $\mathbf{n}$ & $\%$ & $\mathbf{n}$ & $\%$ \\
\hline $\begin{array}{l}\text { GIT } \\
\text { Medical } \\
\text { prophylaxis }\end{array}$ & 104 & 60.8 & 5 & 1.8 & 22 & 4.9 \\
\hline $\begin{array}{l}\text { Others } \\
\text { Respiratory }\end{array}$ & 2 & 1.2 & 6 & 2.2 & 8 & 1.8 \\
\hline $\begin{array}{l}\text { Skin and soft } \\
\text { tissue infection }\end{array}$ & 8 & 4.6 & 29 & 10.6 & 37 & 8.3 \\
\hline $\begin{array}{l}\text { Surgical } \\
\text { Prophylaxis }\end{array}$ & 2 & 1.2 & 90 & 32.8 & 92 & 20.6 \\
\hline $\begin{array}{l}\text { Urinary } \\
\text { Total }\end{array}$ & 6 & 3.5 & 2 & 0.7 & 8 & 1.8 \\
\hline
\end{tabular}


Vol. 10 No. $2: 2$

doi: $10.3823 / 845$

Table 3. Distribution of antimicrobial agents.

\begin{tabular}{|c|c|c|c|c|c|c|}
\hline \multirow{2}{*}{$\begin{array}{c}\text { Antibiotics } \\
\text { generic names }\end{array}$} & \multicolumn{2}{|c|}{ Nepal } & \multicolumn{2}{|c|}{ Pakistan } & \multicolumn{2}{|c|}{ Total } \\
\hline & $\mathrm{n}$ & $\%$ & $n$ & $\%$ & $n$ & $\%$ \\
\hline Amoxicillin & 6 & 3.5 & 0 & 0 & 6 & 1.3 \\
\hline $\begin{array}{l}\text { Amoxicillin + } \\
\text { Clavulanic acid }\end{array}$ & 12 & 6.9 & 23 & 8.4 & 35 & 7.7 \\
\hline Ampicillin & 0 & 0 & 13 & 4.7 & 13 & 2.8 \\
\hline Cloxacillin & 6 & 3.5 & 0 & 0 & 6 & 1.3 \\
\hline $\begin{array}{l}\text { Piperacillin } \mathrm{Na}+ \\
\text { Tazobactam } \mathrm{Na}\end{array}$ & 3 & 1.7 & 1 & 0.4 & 4 & 0.9 \\
\hline Meropenem & 1 & 0.6 & 8 & 2.9 & 9 & 2.0 \\
\hline Azithromycin & 15 & 8.7 & 7 & 2.6 & 22 & 4.8 \\
\hline Cefuroxime & 3 & 1.7 & 5 & 1.8 & 8 & 1.8 \\
\hline Cefixime & 3 & 1.7 & 3 & 1.1 & 6 & 1.3 \\
\hline Cefoperazone & 0 & 0 & 20 & 7.3 & 20 & 4.4 \\
\hline $\begin{array}{l}\text { Cefoperazone + } \\
\text { Sulbactam }\end{array}$ & 0 & 0 & 4 & 1.5 & 4 & 0.8 \\
\hline Cefotaxime & 12 & 6.9 & 0 & 0 & 12 & 2.6 \\
\hline Cefpodoxime & 13 & 7.5 & 0 & 0 & 13 & 2.8 \\
\hline Ceftriaxone & 39 & 22.5 & 101 & 36.9 & 140 & 30.6 \\
\hline Ciprofloxacin & 8 & 4.6 & 15 & 5.5 & 23 & 5.0 \\
\hline Moxifloxacin & 1 & 0.6 & 7 & 2.6 & 8 & 1.8 \\
\hline Amikacin & 0 & 0 & 5 & 1.8 & 5 & 1.1 \\
\hline Gentamicin & 5 & 2.9 & 6 & 2.2 & 11 & 2.4 \\
\hline Clindamycin & 4 & 2.3 & 0 & 0 & 4 & 0.9 \\
\hline Doxycycline & 5 & 2.9 & 1 & 0.4 & 6 & 1.3 \\
\hline Metronidazole & 16 & 9.2 & 36 & 13.1 & 52 & 11.4 \\
\hline Vancomycin & 0 & 0 & 4 & 1.5 & 4 & 0.9 \\
\hline $\begin{array}{l}\text { Other } \\
\text { antimicrobial } \\
\text { agents }\end{array}$ & 21 & 12.6 & 15 & 5.7 & 36 & 6.6 \\
\hline Total & 173 & 100 & 274 & 100 & 447 & 100 \\
\hline
\end{tabular}

Table 4. Antimicrobial agents prescribed according to EDL of WHO.

\begin{tabular}{|c|c|c|c|c|c|c|}
\hline \multirow{2}{*}{ WHO LIST } & \multicolumn{2}{|c|}{ Nepal } & \multicolumn{2}{|c|}{ Pakistan } & \multicolumn{2}{|c|}{ Total } \\
\hline & $\mathrm{n}$ & $\%$ & $\mathrm{n}$ & $\%$ & $\mathrm{n}$ & $\%$ \\
\hline Key Access Group & 57 & 33.0 & 87 & 31.8 & 144 & 30.6 \\
\hline $\begin{array}{l}\text { Combined } \\
\text { groupKey access } \\
\text { and watch group) }\end{array}$ & 79 & 45.7 & 135 & 49.2 & 214 & 46.4 \\
\hline Watch group & 2 & 1.2 & 11 & 4.0 & 13 & 2.8 \\
\hline Reserved group & 1 & 0.6 & 3 & 1.1 & 4 & 0.9 \\
\hline Not available & 34 & 19.7 & 38 & 13.9 & 72 & 15.8 \\
\hline Total & 173 & 100 & 274 & 100 & 447 & 100 \\
\hline
\end{tabular}

\section{Discussion}

To analyze and compare the pattern and irrational prescribing rate of antibiotics between Pakistan and Nepal, this comparative study was conducted on a small scale in different hospitals of the major cities of Pakistan and Nepal [10]. The data was collected from the prescriptions of 272 ambulatories and admitted patients who were prescribed with 447 antibiotics. The number of antimicrobials prescribed to them is tabulated and categorized based on classes, generations, and indications for which antibiotics were prescribed. Also, the prescribed antibiotics are divided into three groups of Access, watch, and reserve according to the WHO Model List of Essential Medicines (EML). In a study done in Nepal, the data depicts that female patients which were found to be treated with antibiotics were less in number (29.4\%) as compared to male patients (70.6\%) [11]. In Pakistan, a study about self-medication suggests the $80 \%$ males and $20 \%$ female involve in self-medication and among the university students in this category, almost $76 \%$ of them were using antibiotics [12]. In a study on prescribing and dispensing patterns of antibiotics in pharmacies done in Islamabad and Rawalpindi among 386 respondents, 67.9\% were males, and $32.1 \%$ were females. While the data from Pakistan showed $50.8 \%$ female and $49.2 \%$ male [13]. In our study, thirdgeneration cephalosporin's are found to be used mostly (42.3\%). The same pattern found in a study from Spain which also reveals the high use of $3^{\text {rd }}$ generation cephalosporin. The extensive use of $3^{\text {rd }}$ generations cephalosporin causes the emergence of extended-spectrum beta-lactamase enzymes in bacteria those also lead to making antibiotic therapy ineffective [14]. After cephalosporin, penicillin and quinolones are the most commonly used drugs are shown in the same literature. Same observations are obtained in our study as well. These all drugs including carbapenem and meropenem are used to treat high-risk bacterial infections such as nosocomial, ventilator-associated pneumonia and multidrug-resistant microbes causing infections, bloods- 
tream infections etc. $[15,16]$. For the selection of cost-effective, efficient reliable and more beneficial drugs WHO model essential medicines list provides a framework in health care organizations. In our study use of this list, drugs are found to be satisfactory in Pakistan, access to the public for these drugs are made easy by government hospitals and hospital medicines available for free of cost [17]. In national essential medicine of Nepal consists 250 medicine 75 of them are available in lower or primary health care centers some of them are available for free of cost [18, 19]. In our cross-sectional study majority of antibiotics were found to be prescribed for medical prophylaxis, surgical prophylaxis or no provisional diagnosis on prescriptions were made, this trend was found in Pakistan and Nepal whereas literature after studies suggest no significant improvement for prevention of infection by using antibiotic for prophylactic purpose as article concluded that there is no meaningful improvement on pancreatitis in a study done in Nepal for prophylactic use metronidazole and ciprofloxacin [20, 21]. In a randomized study in Finland on the prophylactic use of antibiotics for lactobacillus GG associated diarrhea and respiratory infection is found to be effective when this study relies on the proper diagnosis with the or screening for the causative agent but in our study, we did not found and trend of culture before prescribing antibiotic [22]. The problem of prescribing antibiotics is not only the problems of Pakistan and Nepal this is also found in India and other our neighbor countries and study made conclusion this may lead to the development of antibiotic resistance, so the trend of prescribing multiple antibiotics based on assumption and prediction is very dangerous [23]. In different kinds of literature on the study of prophylactic use of antibiotic, the single use of antibiotics for prevention and minimization of the risk of infections is suggested, but multiple uses are not good effective in view of cost and efficacy [24].

\section{Conclusion}

This study has documented comparative prescriptions of antimicrobials to ambulatory and admitted patients of different hospitals of Pakistan and Nepal. Nearly equal numbers of prescriptions were collected from both countries for a cross-sectional study. The study suggests that the rate of antimicrobial prescription in Pakistan is $7.2 \%$ higher comparatively as compared to Nepal. The rate of antimicrobial prescription to female patients in Nepal is much lower as compared to male patients while in Pakistan almost equal trend is observed for both genders. Moreover, the data also shows that 3rd generation cephalosporins were the most prescribed antimicrobial in both countries. Mix group (Access and watch group) was prescribed most of the times. Also, in both countries, the majority of antibiotics are prescribed for prophylaxis purpose without provisional diagnosis and confirmation of the presence of causative agents to which those antibiotics are prescribed. We would like to recommend that antibiotics should be generally prescribed based on antimicrobial susceptibility investigations in laboratories of private and government hospitals of both countries. The prescribing of multiple antibiotics for prophylaxis purpose is not recommended and should be only used in confirmed infection by culture. The implementation of prudent antibiotic practices should be based on guidelines prepared by health or academic authorities, also periodic training and awareness programs of prudent use of antibiotics by a health professional are highly necessary for each country.

\section{References}

1. Mashhadi S, Hamid S, Roshan R, et al. Healthcare in Pakistan, A System Perspective. P A F M J 2016; 66(1):136-42.

2. Wang J, Wang $P$, Wang $X$, et al, Use and prescription of antibiotics in primary health care settings in China. JAMA Intern Med, 2014. 174(12):1914-1920.

3. Masiero G, Filippini M, Ferech M, Goossens H. Socioeconomic determinants of outpatient antibiotic use in Europe. Int J Public Health 2010; 55(5):469-478. 
4. Marra F, Mak S, Chong M, Patrick DM. The relationship among antibiotic consumption, socioeconomic factors and climatic conditions. Can J Infect Dis Med Microbiol 2010; 21(3): e99-e106. doi: 10.1155/2010/965268.

5. Krushna Chandra Sahoo KC, Tamhankar AJ, Johansson E, Lundborg SC. Antibiotic use, resistance development and environmental factors: a qualitative study among healthcare professionals in Orissa, India. BMC Public Health 2010; 10(1):629.

6. Marra F, Mak S, Chong M, et al. The relationship among antibiotic consumption, socioeconomic factors and climatic conditions. Can J Infect Dis Med Microbiol. 2010; 21(3):e99-e106.

7. Klein EY, Van Boeckel TP, Martinez EM, et al. Global increase and geographic convergence in antibiotic consumption between 2000 and 2015. Proceedings of the National Academy of Sciences, 2018: p. e3463-e3470.

8. Thapa S, Sapkota LB. Changing trend of neonatal septicemia and antibiotic susceptibility pattern of isolates in Nepal. 2019 (Article ID: 3784529).

9. Muhammad I, Uzma M, Yasmin B, et al. Prevalence of antimicrobial resistance and integrons in Escherichia Coli from Punjab, Pakistan. Braz. J. Microbiol 2011; 42: p. 462-466.

10. Saleem Z, Saeed H, Ahmad M, et al. Antibiotic Self-Prescribing Trends, Experiences and Attitudes in Upper Respiratory Tract Infection among Pharmacy and Non-Pharmacy Students: A Study from Lahore. PloS one, 2016; 11(2): p. e0149929.

11. Thapaliya K, Shrestha S, Bhattarai S, et al., Prescribing pattern of antibiotics in pediatric hospital in Chitwan district in Nepal. World J Pharm Pharmaceut Sci, 2015; 4(11): p. 1631-1641.

12. Hanif A, Ashar MS, Rabnawaz Rana, et al., Self-medication of Antibiotics among the Students of Hamdard University, Pakistan. J Public Health Develop Count 2016; 2(1): p. 145-148.

13. Imtiaz F, Hafeez A, Ashraf F, et al., Antibiotic Dispensing and Prescription Pattern in Pharmacies of Islamabad and Rosalind: Pakistan. Int J Collabor Res on Inter Med Public Health, 2017; 9 (5): 683-693.

14. Pinto Pereira LM, Phillips $M$, Ramlal $H$, et al. Third generation cephalosporin use in a tertiary hospital in Port of Spain, Trinidad: need for an antibiotic policy. BMC Infect Dis. 2004; 4(1):59.

15. Tumbarello M, Spanu T, Sanguinetti $M$, et al. Bloodstream infections caused by extended-spectrum-beta-lactamaseproducing Klebsiella pneumonia: risk factors, molecular epidemiology, and clinical outcome. Antimicrob Agents Chemother. 2006; 50(2):498-504.

16. Trouillet J L, Chastre J, Vuagnat A, et al. Ventilator-associated pneumonia caused by potentially drug-resistant bacteria. Am J Respir Crit Care Med. 1998; 157(2):531-9.

17. Zaidi S, Bigdeli M, Aleem N, et al. Access to Essential Medicines in Pakistan: Policy and Health Systems Research Concerns. PLoS ONE 2013; 8(5): e6351518.
18. Chaulagai, C.N, Community financing for essential drugs in Nepal. World Health Forum. 1995; 16: 92-94.

19. Mendis S, Fukino K, Cameron A, et al. The availability and affordability of selected essential medicines for chronic diseases in six low-and middle-income countries. Bull World Health Org 2007; 85(4):279-288.

20. Mandal A.K, Chaudhary S, Shrestha B, et al., Efficacy of prophylactic use of ciprofloxacin and metronidazole in mild and moderately severe acute pancreatitis. J Nepal MedAsso 2017; 56:207-210.

21. Saleem Z, Hassali AM, Hashmi KF. Pakistan's national action plan for antimicrobial resistance: translating ideas into reality. The Lancet Infect Dis 2018; 18(10):1066-1067.

22. Arvola T, Laiho K, Torkkeli S, et al. Prophylactic Lactobacillus GG reduces antibiotic-associated diarrhea in children with respiratory infections: a randomized study. Pediatrics. 1999; 104(5):e64.

24. Landstedt K, Sharma A, Johansson F. Antibiotic prescriptions for inpatients having non-bacterial diagnosis at medicine departments of two private sector hospitals in Madhya Pradesh, India: a cross-sectional study. BMJ Open 2017; 7:e012974.

25. McDonald M, Grabsch E, Marshall C, Forbes A. Single- versus multiple-dose antimicrobial prophylaxis for major surgery: a systematic review. Aust N Z J Surg 1998; 68(6):388-396.

\section{Publish in The International}

Arabic Journal of Antimicrobial Agents

The Journal is an open access peer-reviewed journal that publishes scientific papers about all aspects of antimicrobials. The journal will publish original research articles, reviews, brief reports and case reports dealing with basic and clinical antibacterial agents, antiviral, antiprotozoals, antituberculuous, antifungal and antihelminthes agents. All manuscripts must be prepared in English, and are subject to a rigorous and fair peer-review process. Accepted papers will immediately appear online. The journal aims to advance the knowledge, attitude and the research of chemotherapy in the Arabic world in cooperation with international, national scientific and public societies as well as research centers with similar aims and objectives. 